\title{
Do physical exercise and reading reduce the risk of Parkinson's disease? a cross-sectional study on factors associated with Parkinson's disease in elderly Chinese veterans
}

\author{
This article was published in the following Dove Press journal: \\ Neuropsychiatric Disease and Treatment \\ 16 March 2015 \\ Number of times this article has been viewed
}

\section{YM Zou' \\ JP $\operatorname{Tan}^{2}$ \\ $\mathrm{N} \mathrm{Li}{ }^{3}$ \\ JS Yang ${ }^{4}$ \\ $B C \mathrm{Yu}^{5}$ \\ JMYu ${ }^{6}$ \\ YM Zhao ${ }^{3}$ \\ LN Wang ${ }^{2}$ \\ 'Department of Neurology, Huanhu Hospital, Tianjin, ${ }^{2}$ Department of Geriatric Neurology, Chinese PLA General Hospital, ${ }^{3}$ Research Center of Clinical Epidemiology, Peking University Third Hospital, Beijing, ${ }^{4}$ Department of Neurology, General Hospital of Lanzhou Military Command, Lanzhou, ${ }^{5}$ Department of Gerontology, Bethune International Peace Hospital, Shijiazhuang, ${ }^{6}$ Department of Neurology, Chinese PLA 107 Hospital, Yantai, People's Republic of China}

Background: The purpose of this study was to investigate risk factors for and factors protecting against Parkinson's disease (PD) in elderly Chinese veterans.

Methods: Using a database containing detailed information on the health status of the nervous system in elderly Chinese veterans, univariate and multivariate analyses of factors that may be associated with PD were performed. Univariate analysis of qualitative data was done using the Pearson Chi-square and Fisher's exact tests, and the Mann-Whitney $U$ nonparametric test was used for univariate analysis of quantitative data. Multivariate logistic regression analysis was used to identify independent risk factors for and factors protecting against PD in elderly Chinese veterans.

Results: A total of 9,676 elderly Chinese veterans were enrolled, including 228 cases with PD and 183 cases with Parkinson's syndrome, with 9,265 non-PD subjects serving as controls. Age (odds ratio [OR] 1.343, 95\% confidence interval [CI] 1.028-1.755) and medical history of essential tremor (OR 1.228, 95\% CI 1.081-1.396) were identified as independent risk factors for PD, with age being the most important risk factor. Physical exercise (OR 0.478, 95\% CI $0.355-0.643$ ) and reading (OR $0.513,95 \%$ CI $0.357-0.735$ ) were identified as independent factors protecting against $\mathrm{PD}$, and physical exercise showed better protection against $\mathrm{PD}$ relative to reading. Smoking, alcohol use, anemia, cerebral trauma, education level, and electromagnetic field exposure showed no association with PD.

Conclusion: Physical exercise and reading may be independent factors that protect against PD among elderly Chinese veterans, while advancing age and medical history of essential tremor may be independent risk factors for PD. This study was cross-sectional, so further research is needed to confirm its results.

Keywords: Chinese veterans, Parkinson's disease, physical exercise, reading, age, medical history, essential tremor

\section{Introduction}

Parkinson's disease (PD) is a common degenerative disease of the central nervous system in the middle-aged and elderly population, and ranks second only to Alzheimer's disease. PD has been found to be associated with multiple factors; however, the exact associations between PD and many factors, such as education level, electromagnetic field exposure, and cerebral trauma remain controversial. Potential risk factors for PD have been extensively investigated, including smoking, ${ }^{1-5}$ drinking coffee,${ }^{6-8}$ use of insecticides, ${ }^{9,10}$ exposure to heavy metals, ${ }^{11,12}$ administration of certain drugs, ${ }^{13,14}$ occupation, ${ }^{15,16}$ and cerebral trauma. ${ }^{17-19}$ Until now, there have been few studies from
Correspondence: LN Wang Department of Geriatric Neurology, Chinese PLA General Hospital, Beijing 100853, People's Republic of China Tel +861066876268 Fax +861068229325 Email wangluning30।@I63.com 
the People's Republic of China reporting factors associated with PD, with most being case-control studies and none being large-scale, cross-sectional surveys or prospective cohort studies. In addition, the majority of epidemiological surveys on PD reported for the People's Republic of China have focused mainly on the prevalence and incidence of the disease, ${ }^{20-23}$ with only a minority investigating its etiology. In recent years, studies examining risk factors for PD have concentrated mainly on the mutant loci of certain genes, ${ }^{24,25}$ while few large-scale epidemiological surveys have evaluated the relationship between sociodemographic factors, disease factors, and PD in the People's Republic of China. Studies done to identify factors associated with PD in special populations, eg, elderly Chinese veterans, are rare. A cross-sectional study in Urumqi city and the Yili region (in Xinjiang autonomous region) revealed that eating barbequed food may be a risk factor of $\mathrm{PD}$, while drinking tea and dietary diversity may protect against PD. ${ }^{26,27}$ Further, the prevalence of PD was found not to be associated with age, but was significantly associated with level of education, in a cross-sectional study of veterans in the Shijiazhuang region. ${ }^{28}$ To identify risk factors for and factors protecting against PD in elderly Chinese veterans, we conducted a cross-sectional study in this age group and established a database. ${ }^{29}$ We investigated the risk factors for and factors protecting against PD based on information concerning the health status of the nervous system in elderly Chinese veterans contained in the database, so as to be able to provide an evidence-based strategy for the prevention and control of PD in elderly Chinese veterans.

\section{Patients and methods}

Epidemiological data pertaining to PD were extracted from a database containing data on the health status of the nervous system for elderly Chinese veterans. ${ }^{29}$ The clinical diagnosis of PD or other parkinsonism was made by a neurology panel comprising the heads of the participating institutions, based on disease history and physical and ancillary examinations. Diagnosis of PD was made according to the diagnostic criteria of the UK Parkinson's Disease Society Brain Bank. ${ }^{30}$ Univariate analysis of qualitative data was done using the Pearson Chi-square and Fisher's exact tests, and the Mann-Whitney $U$ nonparametric test was used for univariate analysis of quantitative data. A logistic regression model was used with multivariate analysis, and odds ratios (ORs) and 95\% confidence intervals (CIs) were calculated. All statistical analyses were performed using Statistical Package for the Social Sciences version 18.0 software (SPSS Inc, Chicago, IL, USA).

\section{Results}

In this population-based case-control study, 9,676 elderly Chinese veterans were recruited, including 228 cases with PD, 183 cases with Parkinson's syndrome, and 9,265 subjects without PD who served as controls; 183 ineligible cases with Parkinson's syndrome were excluded. There were no significant differences detected in sex, ethnicity, education level, or marital status between the PD and control groups, but there was a significant difference in mean age (see Table 1). All factors potentially associated with development of PD were included in the univariate analysis, and a total of 17 factors were identified (Table 2). The factors screened above and those unrelated to PD revealed by univariate analysis but receiving much attention (including educational level, electromagnetic field exposure, and cerebral trauma), were included in the multivariate logistic regression analysis to examine their associations with PD, and four independent factors were found to correlate with PD. Our findings showed that age (OR 1.343, 95\% CI 1.028-1.755) and a medical history of essential tremor (OR 1.228, 95\% CI 1.081-1.396) were independent risk factors of $\mathrm{PD}$, and physical exercise (OR 0.478, 95\% CI 0.355-0.643) and reading (OR 0.513, 95\% CI 0.357-0.735) were independent factors protecting against PD (Table 3). Smoking, alcohol use, anemia, cerebral trauma, education level, and history and duration of electromagnetic field exposure showed no association with PD.

\section{Discussion}

Many factors are reported to contribute to the development of PD, but different results are reported by various epidemiological studies. In the current study, two independent risk factors (age and medical history of essential tremor) and two factors protecting against PD (physical exercise and reading) were identified. Multiple studies have demonstrated that age $\mathrm{e}^{20,22,31,32}$ and a history of essential tremor ${ }^{33-36}$ are independent risk factors for PD. Our present findings contribute new evidence to support age and medical history of essential tremor as independent risk factors for PD.

Our findings show that the best protection against PD is afforded by physical exercise. In this study, optimal physical exercise involved exercising for more than 2 hours per day, in particular walking, jogging, dancing, swimming, playing ping pong, and performing Tai-Chi. There are no strict restrictions regarding the form of physical exercise. The proportion of subjects exercising for over 2 hours daily was significantly $(P<0.001)$ higher in the control group (83.1\%) when compared with the PD group (69.3\%). This finding is in agreement with the results from three previous 
Table I Comparison of demographic features between elderly Chinese veterans with and without PD

\begin{tabular}{|c|c|c|c|c|c|c|c|c|}
\hline & \multicolumn{2}{|c|}{ Control group } & \multicolumn{2}{|c|}{ PD group } & \multicolumn{2}{|l|}{ Total } & \multirow{2}{*}{$\begin{array}{l}\chi^{2} / \text { Fisher's } \\
\text { exact test }\end{array}$} & \multirow[t]{2}{*}{$P$-value } \\
\hline & $\mathrm{n}$ & $\%$ & $\mathbf{n}$ & $\%$ & $\mathrm{n}$ & $\%$ & & \\
\hline Sex & & & & & & & 1.682 & 0.195 \\
\hline Male & 8,696 & 95.59 & 222 & 97.37 & 8,918 & 95.64 & & \\
\hline Female & 401 & 4.41 & 6 & 2.63 & 407 & 4.36 & & \\
\hline Race & & & & & & & 7.11 & 0.175 \\
\hline Han & 8,868 & 97.74 & 220 & 96.49 & 9,088 & 97.71 & & \\
\hline Other race & 205 & 2.26 & 8 & 3.51 & 213 & 2.29 & & \\
\hline Age (years) & & & & & & & 10.19 & 0.015 \\
\hline$<70$ & 120 & 1.33 & 0 & 0.00 & 120 & 1.30 & & \\
\hline $70-79$ & 2,477 & 27.53 & 47 & 20.89 & 2,524 & 27.37 & & \\
\hline $80-89$ & 6,118 & 68.00 & 167 & 74.22 & 6,285 & 68.15 & & \\
\hline$\geq 90$ & 282 & 3.13 & 11 & 4.89 & 293 & 3.18 & & \\
\hline Education level (years) & & & & & & & 3.32 & 0.19 \\
\hline$<7$ & 3,684 & 40.21 & 88 & 38.60 & 3,772 & 40.17 & & \\
\hline $7-12$ & 3,982 & 43.46 & 111 & 48.68 & 4,093 & 43.59 & & \\
\hline$>12$ & 1,496 & 16.33 & 29 & 12.72 & 1,525 & 16.24 & & \\
\hline Marital status & & & & & & & 0.879 & 0.961 \\
\hline Never married & 36 & 0.40 & I & 0.44 & 37 & 0.40 & & \\
\hline Married, living with spouse & 7,484 & 82.81 & 190 & 83.33 & 7,674 & 82.82 & & \\
\hline Married, not living with spouse & 94 & 1.04 & 3 & 1.32 & 97 & 1.05 & & \\
\hline Divorced & 23 & 0.25 & 0 & 0 & 23 & 0.25 & & \\
\hline Death of spouse & 1,106 & 12.24 & 29 & 12.72 & 1,135 & 12.25 & & \\
\hline Remarried & 266 & 2.94 & 5 & 2.19 & 271 & 2.92 & & \\
\hline Unknown & 29 & 0.32 & 0 & 0 & 29 & 0.31 & & \\
\hline
\end{tabular}

Notes: Sex missing for case 168; race missing case for 192; age missing for case 27।; education missing case for 103 ; marital status missing for case 227.

Abbreviation: PD, Parkinson's disease.

large-scale cohort studies reporting that moderate-intensity and high-intensity physical exercise can markedly decrease the risk of PD. ${ }^{37-39}$ Retrospective analyses showed a comparable efficacy of physical exercise to smoking and coffee drinking in reducing the risk of $\mathrm{PD},{ }^{40,41}$ although the underlying mechanisms may be different. It has been reported that physical exercise may exert its protective effect by promoting nerve cell regeneration ${ }^{42-44}$ and improving neural cell plasticity; ${ }^{45,46}$ however, further studies are required to clarify the exact mechanisms. It has been demonstrated that

Table 2 Results of univariate analyses and screened the factors related to PD

\begin{tabular}{|c|c|c|c|c|}
\hline Factors & Control group & PD group & $\begin{array}{l}\chi^{2} / \text { Fisher's } \\
\text { exact test }\end{array}$ & P-value \\
\hline Age, years & 81.97 & 82.85 & 10.188 & 0.015 \\
\hline Physical exercise & $83.1 \%$ & $69.3 \%$ & 29.800 & $<0.001$ \\
\hline Mean duration of daily exercises & $14.5 \%$ & $8.5 \%$ & 15.149 & 0.001 \\
\hline Reading & $90.3 \%$ & $80.7 \%$ & 19.729 & $<0.001$ \\
\hline Take part in social activities & $37.4 \%$ & $25.9 \%$ & 13.674 & $0.00 \mathrm{I}$ \\
\hline Keep small animals like fish or birds & $17.1 \%$ & $10.1 \%$ & 8.367 & 0.015 \\
\hline Watch television, listen to broadcasts & $93.2 \%$ & $88.2 \%$ & 8.265 & 0.015 \\
\hline History of alcohol consumption & $45.4 \%$ & $47.8 \%$ & 10.832 & 0.026 \\
\hline History of hypotension & $3.2 \%$ & $6.2 \%$ & 7.243 & 0.027 \\
\hline History of essential tremor & $1.3 \%$ & $7.5 \%$ & 39.167 & $<0.001$ \\
\hline History of depression & $1.3 \%$ & $4.4 \%$ & $|0.78|$ & 0.003 \\
\hline History of anemia & $3.7 \%$ & $7.5 \%$ & 7.261 & 0.024 \\
\hline Family history of dementia & $1.3 \%$ & $2.7 \%$ & 10.886 & 0.024 \\
\hline Family history of PD & $0.3 \%$ & $2.2 \%$ & 26.022 & $<0.001$ \\
\hline Family history of essential tremor & $0.3 \%$ & $0.9 \%$ & 9.941 & 0.034 \\
\hline History of migraine & $4.3 \%$ & $6.6 \%$ & 8.564 & 0.012 \\
\hline History of coronary artery disease & $68.9 \%$ & $76.8 \%$ & 6.608 & 0.031 \\
\hline
\end{tabular}

Notes: Age, 50th percentile; mean daily exercise duration, over 2 hours daily as a standard.

Abbreviation: PD, Parkinson's disease. 
Table 3 Results of multivariate logistic regression analysis

\begin{tabular}{|c|c|c|c|c|c|c|}
\hline Factors & B & SE & Wald & $P$-value & OR & $95 \% \mathrm{Cl}$ \\
\hline Physical examination & -0.738 & 0.152 & 23.686 & $<0.001$ & 0.478 & $0.355-0.643$ \\
\hline History of essential tremor & 0.206 & 0.065 & 9.973 & 0.002 & 1.228 & $1.081-1.396$ \\
\hline Reading & -0.668 & 0.184 & 13.194 & $<0.001$ & 0.513 & $0.357-0.735$ \\
\hline Age & 0.295 & 0.136 & 4.679 & 0.031 & 1.343 & I.028-I.755 \\
\hline Constant & -2.975 & 0.61 & 23.711 & $<0.001$ & 0.051 & - \\
\hline
\end{tabular}

Abbreviations: $\mathrm{Cl}$, confidence interval; OR, odds ratio; SE, standard error.

physical exercise can improve the motor symptoms of $\mathrm{PD}$, and cycling ${ }^{47}$ and Tai Chi exercise ${ }^{48}$ have been shown to improve gait disorders and disequilibrium in patients with $\mathrm{PD}$, underscoring the ability of physical exercise to protect against $P D$. In addition, the intensity of physical exercise has been shown to correlate strongly with occupation, and occupations involving high-intensity physical exercise have been demonstrated to reduce the risk of PD. ${ }^{15}$ However, although there is now good evidence showing that physical exercise can reduce the risk of $\mathrm{PD}$, there is no direct evidence that physical exercise can slow the progression of the disease, which is supported by the results from a few clinical trials.

Reading is an intellectual activity, and most of the previous studies have focused on the cognitive domain. Reading is reported to improve cognition and to reduce the risk of dementia. ${ }^{49-51}$ Reading level has recently been identified as a reliable predictor of executive and cognitive function, and is considered to be a good method for measuring cognitive reserve..$^{52}$ There are a few studies reporting a correlation between reading and $\mathrm{PD}$, but there is no previous research identifying reading as an independent factor protecting against PD. In our study, reading included books and newspapers, and there was no specific time limit for this habit/ hobby. Our findings show that reading is an independent factor protecting against $\mathrm{PD}$, and a significantly greater amount of reading was observed in the control group (90.3\%) when compared with the PD group $(80.7 \% ; P<0.001)$. Although further studies are required to investigate the mechanism for this, the finding that reading is an independent factor protecting against PD provides a potential, simple, and easy-to-use method for prevention of PD. Generally, reading habits are associated with educational level. Our observations show reading to be an independent factor protecting against PD, but no correlation between education level and PD was detected. The relationship between educational level and PD remains controversial. Education level has been reported not to correlate with the risk of $\mathrm{PD},{ }^{53}$ but Frigerio et $\mathrm{al}^{15}$ reported that higher education increased the risk of
PD, and suggested that this might be due to subjects with higher education participating in less physical activity. Our findings support the conclusion reached by Rocca et $\mathrm{al}^{53}$ but further studies are needed to investigate the exact relationship between education and PD.

It has been shown that electromagnetic field exposure may correlate with $\mathrm{PD},{ }^{54}$ but our findings do not support this relationship. In our study, neither electromagnetic field exposure nor its duration correlated with development of $\mathrm{PD}$, which is consistent with the results of most previous studies. ${ }^{55,56}$ Further, we found that smoking, alcohol use, anemia, hypotension, depression, migraine, and coronary heart disease were not independent risk factors for PD.

To our knowledge, this study is the first large-scale survey of risk factors for and factors protecting against PD in elderly Chinese veterans in the People's Republic of China. Detailed clinical data and involvement of professional medical teams ensured the reliability and accuracy of the study results. Few studies have reported such detailed medical information on the health status of the nervous system in an elderly Chinese population in the People's Republic of China. Our findings identify two independent risk factors for and two factors protecting against the development of PD in elderly Chinese veterans, and to the authors' knowledge, this is the first study reporting reading as an independent factor protecting against PD in the People's Republic of China. Our findings are of value for the prevention and control of PD in elderly Chinese veterans.

\section{Acknowledgments}

The authors thank the patients who participated in this study, which was supported by grants (07BJZ04, 10BJZ19, 11BJZ09, 12BJZ46) from the Special Health Research Foundation of the Health Department of the PLA General Logistics Department.

\section{Disclosure}

The authors report no conflicts of interest in this work. 


\section{References}

1. Chen H, Huang X, Guo X, et al. Smoking duration, intensity, and risk of Parkinson disease. Neurology. 2010;74:878-884.

2. Searles Nielsen S, Gallagher LG, Lundin JI, et al. Environmental tobacco smoke and Parkinson's disease. Mov Disord. 2012;27:293-296.

3. Tanaka K, Miyake Y, Fukushima W, et al. Active and passive smoking and risk of Parkinson's disease. Acta Neurol Scand. 2010;122:377-382.

4. O'Reilly EJ, Chen H, Gardener H, Gao X, Schwarzschild MA, Ascherio A. Smoking and Parkinson's disease: using parental smoking as a proxy to explore causality. Am J Epidemiol. 2009;169:678-682.

5. Ritz B, Ascherio A, Checkoway H, et al. Pooled analysis of tobacco use and risk of Parkinson disease. Arch Neurol. 2007;64:990-997.

6. Palacios N, Gao X, McCullough ML, et al. Caffeine and risk of Parkinson's disease in a large cohort of men and women. Mov Disord. 2012;27:1276-1282.

7. Qi H, Li S. Dose-response meta-analysis on coffee, tea and caffeine consumption with risk of Parkinson's disease. Geriatr Gerontol Int. 2014;14:430-439.

8. Liu R, Guo X, Park Y, et al. Caffeine intake, smoking, and risk of Parkinson disease in men and women. Am J Epidemiol. 2012;175:1200-1207.

9. Pezzoli G, Cereda E. Exposure to pesticides or solvents and risk of Parkinson disease. Neurology. 2013;80:2035-2041.

10. Firestone JA, Smith-Weller T, Franklin G, Swanson P, Longstreth WT Jr, Checkoway H. Pesticides and risk of Parkinson disease: a populationbased case-control study. Arch Neurol. 2005;62:91-95.

11. Mortimer JA, Borenstein AR, Nelson LM. Associations of welding and manganese exposure with Parkinson disease: review and meta-analysis. Neurology. 2012;79:1174-1180.

12. Gorell JM, Johnson CC, Rybicki BA, et al. Occupational exposures to metals as risk factors for Parkinson's disease. Neurology. 1997;48:650-658.

13. Gao X, Chen H, Schwarzschild MA, Ascherio A. Use of ibuprofen and risk of Parkinson disease. Neurology. 2011;76:863-869.

14. Gao X, Simon KC, Schwarzschild MA, Ascherio A. Prospective study of statin use and risk of Parkinson disease. Arch Neurol. 2012;69:380-384.

15. Frigerio R, Elbaz A, Sanft KR, et al. Education and occupations preceding Parkinson disease: a population-based case-control study. Neurology. 2005;65:1575-1583.

16. Tanner CM, Ross GW, Jewell SA, et al. Occupation and risk of parkinsonism: a multicenter case-control study. Arch Neurol. 2009;66:1106-1113.

17. Rugbjerg K, Ritz B, Korbo L, Martinussen N, Olsen JH. Risk of Parkinson's disease after hospital contact for head injury: population based case-control study. BMJ. 2008;337:a2494.

18. Bower JH, Maraganore DM, Peterson BJ, McDonnell SK, Ahlskog JE, Rocca WA. Head trauma preceding PD: a case-control study. Neurology. 2003;60:1610-1615.

19. Lee PC, Bordelon Y, Bronstein J, Ritz B. Traumatic brain injury, paraquat exposure, and their relationship to Parkinson disease. Neurology. 2012;79:2061-2066.

20. Zhang ZX, Roman GC, Hong Z, et al. Parkinson's disease in China: prevalence in Beijing, Xian, and Shanghai. Lancet. 2005;365:595-597.

21. Wang LN, Tan JP, Xie HG, et al. [A cross-sectional study of neurological disease in the veterans of military communities in Beijing]. Zhong Hua Nei Ke Za Zhi. 2010;49:463-468. Chinese.

22. Chen RC, Chang SF, Su CL, et al. Prevalence, incidence, and mortality of PD: a door-to-door survey in Ilan County, Taiwan. Neurology. 2001;57:1679-1686.

23. Wang Y. [The incidence and prevalence of Parkinson's disease in the People's Republic of China]. Zhonghua Liu Xing Bing Xue Za Zhi. 1991;12:363-365. Chinese.

24. Tseng WE, Chen CM, Chen YC, Yi Z, Tan EK, Wu YR. Genetic variations of GAK in two Chinese Parkinson's disease populations: a case-control study. PLoS One. 2013;8:e67506.
25. Cai J, Lin Y, Chen W, et al. Association between G2385R and R1628P polymorphism of LRRK2 gene and sporadic Parkinson's disease in a Han-Chinese population in south-eastern China. Neurol Sci. 2013;34:2001-2006.

26. Wang Lu-N, Zhang T-F, Wang Y-L, Yang X-L. [Study on the prevalence and relative factors of Parkinson's disease in residents aged 35 years or older in Urumqi City]. Journal of Xinjiang Medical University. 2013;36:278-281. Chinese.

27. Zhang J-L, Wang Y-Y, Yao Y-Y, Yang X-L. [Analysis of prevalence and related factors in different national Parkinson's disease in Yili of Xinjiang area]. Journal of Xinjiang Medical University. 2013;36:273-277. Chinese.

28. Yu B-C, He J-Z, Cheng P, Fang H-Z, Wei Y, Wang Z. Prevalence of Parkinson's disease in elderly veterans in China. Healthcare Innovation. 2007;2:102-103.

29. Tan J-P, Li N, Gao J, et al. Construction of the Chinese Veteran Clinical Research (CVCR) platform for the assessment of non-communicable diseases. Chin Med J (Engl). 2014;127:448-456.

30. Hughes AJ, Daniel SE, Kilford L, Lees AJ. Accuracy of clinical diagnosis of idiopathic Parkinson's disease: a clinico-pathological study of 100 cases. J Neurol Neurosurg Psychiatry. 1992;55:181-184.

31. de Rijk MC, Breteler MM, Graveland GA, et al. Prevalence of Parkinson's disease in the elderly: the Rotterdam Study. Neurology. 1995;45:2143-2146.

32. Chen CC, Chen TF, Hwang YC, et al. Different prevalence rates of Parkinson's disease in urban and rural areas: a population-based study in Taiwan. Neuroepidemiology. 2009;33:350-357.

33. Koller WC, Busenbark K, Miner K. The relationship of essential tremor to other movement disorders: report on 678 patients. Essential Tremor Study Group. Ann Neurol. 1994;35:717-723.

34. Louis ED, Frucht SJ. Prevalence of essential tremor in patients with Parkinson's disease vs Parkinson-plus syndromes. Mov Disord. 2007;22:1402-1407.

35. Tan EK, Lee SS, Fook-Chong S, Lum SY. Evidence of increased odds of essential tremor in Parkinson's disease. Mov Disord. 2008;23:993-997.

36. Benito-León J, Louis ED, Bermejo-Pareja F; Neurological Disorders in Central Spain Study Group. Risk of incident Parkinson's disease and parkinsonism in essential tremor: a population based study. $J$ Neurol Neurosurg Psychiatry. 2009;80:423-425.

37. Chen H, Zhang SM, Schwarzschild MA, Hernán MA, Ascherio A. Physical activity and the risk of Parkinson disease. Neurology. 2005; 64:664-669.

38. Thacker EL, Chen H, Patel AV, et al. Recreational physical activity and risk of Parkinson's disease. Mov Disord. 2008;23:69-74.

39. Xu Q, Park Y, Huang X, et al. Physical activities and future risk of Parkinson disease. Neurology. 2010;75:341-348.

40. Ahlskog JE. Does vigorous exercise have a neuroprotective effect in Parkinson disease? Neurology. 2011;77:288-294.

41. Hernán MA, Takkouche B, Caamaño-Isorna F, Gestal-Otero JJ. A meta-analysis of coffee drinking, cigarette smoking, and the risk of Parkinson's disease. Ann Neurol. 2002;52:276-284.

42. O'Dell SJ, Gross NB, Fricks AN, Casiano BD, Nguyen TB, Marshall JF. Running wheel exercise enhances recovery from nigrostriatal dopamine injury without inducing neuroprotection. Neuroscience. 2007;144:1141-1151.

43. Al-Jarrah M, Pothakos K, Novikova L, et al. Endurance exercise promotes cardiorespiratory rehabilitation without neurorestoration in the chronic mouse model of parkinsonism with severe neurodegeneration. Neuroscience. 2007;149:28-37.

44. Pothakos K, Kurz M, Lau Y-S. Restorative effect of endurance exercise on behavioral deficits in the chronic mouse model of Parkinson's disease with severe neurodegeneration. BMC Neurosci. 2009;10:6.

45. Allen DM, van Praag H, Ray J, et al. Ataxia telangiectasia mutated is essential during adult neurogenesis. Genes Dev. 2001;15:554-566. 
46. Rhodes JS, van Praag H, Jeffrey S, et al. Exercise increases hippocampal neurogenesis to high levels but does not improve spatial learning in mice bred for increased voluntary wheel running. Behav Neurosci. 2003;117:1006-1016.

47. Shulman LM, Katzel LI, Ivey FM, et al. Randomized clinical trial of 3 types of physical exercise for patients with Parkinson disease. JAMA Neurol. 2013;70:183-190.

48. Li F, Harmer P, Fitzgerald K, et al. Tai chi and postural stability in patients with Parkinson's disease. N Engl J Med. 2012;366:511-519.

49. Le Goff M, Helmer C, Foubert-Samier A, Cowppli-Bony P, Berr C, Dartigues JF. [Activities in retired people and the risk of dementia]. C R Biol. 2009;332:378-384. French.

50. Lopes MA, Ferrioli E, Nakano EY, Litvoc J, Bottino CM. High prevalence of dementia in a community-based survey of older people from Brazil: association with intellectual activity rather than education. J Alzheimers Dis. 2012;32:307-316.

51. Stern C, Munn Z. Cognitive leisure activities and their role in preventing dementia: a systematic review. Int $J$ Evid Based Healthc. 2010;8:2-17.
52. Soto-Añari M, Flores-Valdivia G, Fernández-Guinea S. Level of reading skills as a measure of cognitive reserve in elderly adults. Rev Neurol. 2013;56:79-85.

53. Rocca WA, Anderson DW, Meneghini F, et al. Occupation, education, and Parkinson's disease: a case-control study in an Italian population. Mov Disord. 1996;11:201-206.

54. Noonan CW, Reif JS, Yost M, Touchstone J. Occupational exposure to magnetic fields in case-referent studies of neurodegenerative diseases. Scand J Work Environ Health. 2002;28:42-48.

55. Johansen C. Exposure to electromagnetic fields and risk of central nervous system disease in utility workers. Epidemiology. 2000;11: 539-543.

56. Huss A, Spoerri A, Egger M, Röösli M; Swiss National Cohort Study. Residence near power lines and mortality from neurodegenerative diseases: longitudinal study of the Swiss population. Am J Epidemiol. 2009; 169:167-175.

\section{Publish your work in this journal}

Neuropsychiatric Disease and Treatment is an international, peerreviewed journal of clinical therapeutics and pharmacology focusing on concise rapid reporting of clinical or pre-clinical studies on a range of neuropsychiatric and neurological disorders. This journal is indexed on PubMed Central, the 'PsycINFO' database and CAS, and is the official journal of The International Neuropsychiatric Association (INA). The manuscript management system is completely online and includes a very quick and fair peer-review system, which is all easy to use. Visit http://www.dovepress.com/testimonials.php to read real quotes from published authors.

Submit your manuscript here: http://www.dovepress.com/neuropsychiatric-disease-and-treatment-journal 